\title{
Variation in the human soluble epoxide hydrolase gene and risk of restenosis after percutaneous coronary intervention
} Silke Kullmann ${ }^{* 1}$, Priska Binner ${ }^{1}$, Kirsten Rackebrandt ${ }^{1}$, Andreas Huge ${ }^{2}$, Georg Haltern', Mark Lankisch ${ }^{3}$, Reiner Füth ${ }^{3}$, Eberhard von Hodenberg ${ }^{4}$, Hans-Peter Bestehorn ${ }^{5}$ and Thomas Scheffold ${ }^{1}$

Address: ${ }^{1}$ Institute for Heart and Circulation Research, University of Witten/Herdecke, 44227 Dortmund, Germany, ${ }^{2}$ Leibniz-Institute for Arteriosclerosis Research, University of Muenster, 48149 Muenster, Germany, ${ }^{3}$ Heart Center Wuppertal Helios-Kliniken, 42117 Wuppertal, Germany, ${ }^{4}$ Internal Medicine/Cardiology, Heart Center Lahr/Baden, 77933 Lahr, Germany and ${ }^{5}$ Heart Center Bad Krozingen, 79189 Bad Krozingen, Germany

Email: Silke Kullmann* - kullmann@herz-kreislaufforschung.de; Priska Binner - binner@herz-kreislaufforschung.de; Kirsten Rackebrandt - rackebrandt@herz-kreislaufforschung.de; Andreas Huge - a.huge@uni-muenster.de; Georg Haltern - georg.haltern@helios-kliniken.de; Mark Lankisch - mark.lankisch@helios-kliniken.de; Reiner Füth - reiner.fueth@helioskliniken.de; Eberhard von Hodenberg - eberhard.hodenberg@heart-lahr.com; Hans-Peter Bestehorn - hans-peter.bestehorn@herzzentrum.de; Thomas Scheffold - scheffold@herz-kreislaufforschung.de

* Corresponding author

Published: 8 October 2009

BMC Cardiovascular Disorders 2009, 9:48 doi:10.1 |86/147|-226|-9-48
Received: 18 May 2009

Accepted: 8 October 2009

This article is available from: http://www.biomedcentral.com/I47I-226I/9/48

(c) 2009 Kullmann et al; licensee BioMed Central Ltd.

This is an Open Access article distributed under the terms of the Creative Commons Attribution License (http://creativecommons.org/licenses/by/2.0), which permits unrestricted use, distribution, and reproduction in any medium, provided the original work is properly cited.

\begin{abstract}
Background: Restenosis represents the major limiting factor for the long-term efficacy of percutaneous coronary intervention $(\mathrm{PCl})$. Several genetic factors involved in the regulation of the vascular system have been described to play a role in the pathogenesis of restenosis. We investigated whether the EPHX2 K55R polymorphism, previously linked to significantly higher risk for coronary heart disease (CHD), was associated with the occurrence of restenosis after $\mathrm{PCl}$. The association with incident $\mathrm{CHD}$ should have been confirmed and a potential correlation of the EPHX2 K55R variant to an increased risk of hypertension was analysed.
\end{abstract}

Methods: An overall cohort of 706 patients was studied: This cohort comprised of $435 \mathrm{CHD}$ patients who had undergone successful PCl. Follow-up coronary angiography in all patients was performed 6 months after intervention. Another 27I patients in whom CHD had been excluded by coronary angiography served as controls. From each patient EDTA-blood was drawn at the baseline ward round. Genomic DNA was extracted from these samples and genotyping was performed by real-time PCR and subsequent melting curve analysis.

Results: In CHD patients 6 month follow-up coronary angiography revealed a restenosis rate of $29.4 \%$, classified as late lumen loss as well as lumen re-narrowing $\geq 50 \%$.

Statistical analysis showed an equal genotype distribution in restenosis patients and non-restenosis patients (A/A $82.0 \%$ and $A / G+G / G 18.0 \%$ versus $A / A$ 82.1\% and A/G + G/G 17.9\%). Moreover, neither a significant difference in the genotype distribution of $\mathrm{CHD}$ patients and controls nor an association with increased risk of hypertension was found.

Conclusion: The results of the present study indicate that the EPHX2 K55R polymorphism is not associated with restenosis after $\mathrm{PCl}$, with incidence of $\mathrm{CHD}$, or with an increased risk of hypertension and therefore, can not serve as a predictor for risk of $\mathrm{CHD}$ or restenosis after $\mathrm{PCl}$. 


\section{Background}

Percutaneous coronary intervention (PCI) is a well established treatment strategy for patients suffering from symptomatic coronary heart disease (CHD). However, in numerous patients restenosis limits the clinical efficacy of this procedure. Restenosis represents a multifactorial process affected by a wide range of clinical, anatomic and procedural factors [1]. This includes, amongst others, the type of intervention such as PCI with or without intracoronary stent placement, type of stent, the nature of the affected vessels and the baseline characteristics of the patients [2-4]. Late lumen loss occurs due to a complex succession of processes, which have only been partially clarified so far. From this, vessel recoil, negative vascular remodelling and neointimal formation contributes to the development of restenosis $[5,6]$.

Beside the classical risk factors and intervention procedures, several reports have demonstrated that genetic factors may be involved in the pathogenesis of restenosis after PCI. Here, gene products which engage in diverse physiological mechanisms, e.g. in the renin-angiotensin system, platelet aggregation, the inflammatory response, and smooth muscle cell proliferation, have been described to be associated with restenosis $[7,8]$.

Several investigations have revealed regulatory functions of arachidonic acid metabolites within the vascular system $[9,10]$. Arachidonic acids are metabolized by cytochrome P450 epoxigenases to hydroxyeicosatetraenoic acids (HETEs) and epoxyeicosatrienoic acids (EETs), particularly in the kidney and vascular endothelium [11]. Among these eicosanoids, EETs represent potent vasodilators playing an important role in the regulation of vascular tone [11-13]. Additionally, EETs have antiinflammatory properties $[14,15]$, inhibit platelet aggregation [16] and promote fibrolysis $[17,18]$.

The degradation of endogenous EETs to their corresponding diols, dihydroxyeicosatrienoic acids (DHETs), is catalyzed by soluble epoxide hydrolase ( $\mathrm{sEH}$ ) encoded by the EPHX2 gene located on chromosome 8p21-p12 [19,20]. Thus, the modulation of EET levels by sEH in the endothelium represents an important mechanism in the regulation of vascular functions. Several studies have validated an association between alterations in EET levels by the modulation of EPHX2 gene expression and cardiovascular risks in animal models and humans. For instance, sequence variation within the EPHX2 gene has been reported to reduce blood pressure in spontaneously hypertensive rats $[21,22]$. EPHX2 knockout mice exhibited significantly lower blood pressure than wild-type mice $[23,24]$. Furthermore, the effect of pharmacological inhibition of sEH in human blood vessels [25] as well as the association between EPHX2 sequence variants and risk of subclinical atherosclerosis has been published $[26,27]$.
Previously, a study reported the correlation of the K55R single nucleotide polymorphism (rs41507953) within the EPHX2 gene with CHD in Caucasians [28]. The authors analysed a total of ten polymorphisms in coding and non-coding regions of EPHX2, which were selected based on their previously published functional relevance in vitro $[29,30]$ and/or haplotype-tagging properties.

The K55R variant within the exon 2 of the EPHX2 gene was shown to be significantly more common among CHD cases than in the controls [28]. Additionally, carriers of the variant allele showed a higher epoxide hydrolase activity in vivo, indicated by lower plasma EET levels. No statistical differences were observed in the comparison of the genotype distribution in CHD cases and controls in the other analysed polymorphisms. Therefore, the findings of this study implicate the EPHX2K55R variant to be a genetic factor which increases the risk of CHD, even though this association has not been confirmed by further studies to date.

Due to the evident effects of EPHX2 in the regulation of vascular function and the association to $\mathrm{CHD}$ in the reported data, we assumed that the $K 55 R$ variant may also be involved into the process of restenosis after percutaneous coronary intervention (PCI).

The main focus of the present project was to analyse whether the EPHX2 K55R variant allele is associated with the occurrence of restenosis within six months after in CHD patients. Moreover, we studied the distribution of genotypic and allelic frequencies of the EPHX2 K55R polymorphism in CHD patients and controls in order to confirm the association of this genetic variant with incident CHD and to analyse a potential correlation with increased risk of hypertension.

\section{Methods}

\section{Study Population}

Patients aged 35-80 years from Central Europe with symptomatic coronary heart disease who had undergone primary successful PCI of a native coronary artery were included into the study as described previously [31]. This multicenter, placebo-controlled study was designed to assess the effect of the calcium channel blocker Verapamil on restenosis after intervention. Successful intervention was defined by residual stenosis $<30 \%$ on visual estimation or desired position of stent. Follow-up coronary angiography was performed 6 months after PCI and the angiograms were quantitatively analysed.

Restenosis was determined through the measurement of the late lumen loss as well as the re-narrowing of the lumen $\geq 50 \%$. 
The study was approved by the local ethic committee and all patients gave written informed consent for further studies.

From this collective, a total of 435 patients, aged 35-79 years, were included into the present study to investigate the potential association between the EPHX2 K55R variant allele and rate of restenosis. Another 271 patients, in whom CHD had been excluded by angiography served as controls.

\section{Blood samples and DNA preparation}

EDTA-blood samples were drawn from each patient at baseline ward round. Genomic DNA was extracted from $350 \mu \mathrm{l}$ of these samples using the BioRobot EZ1 and the EZ1 blood extraction kit according to the manufacturer's instructions (QIAGEN; Hilden, Germany). DNA was quantified using the BioPhotometer (Eppendorf; Hamburg, Germany) and each sample was diluted to a final concentration of $25 \mathrm{ng} / \mu \mathrm{l}$.

\section{PCR amplification and genotyping of EPHX2 K55R}

PCR and detection of the genetic variants of EPHX2 K55R were performed on a LightCycler 480 instrument (Roche Applied Science; Mannheim, Germany) using primers and sequence specific hybridization probes designed and synthesized by TIB MOLBIOL (Berlin, Germany).

PCR was carried out in 96-well plates (Roche Applied Science; Mannheim, Germany) using $62.5 \mathrm{ng}$ of genomic DNA as template in a final reaction volume of $10 \mu \mathrm{l}$.

The reaction mixture contained $0.5 \mu \mathrm{M}$ of each primer (for: 5'-GTGTTTTCCAGAGGACTTCTGA, rev: 5'-GTGACTGCAATACTCCCATTAATA), $0.15 \mu \mathrm{M}$ of SNP-specific hybridization probes (sensor: 5'-LC640-GCTTATGAAAGGAGAGATCACACT-PH; anchor 5'-GGGGACCAGAGGGTGCCACTACCC-FL), and $2 \mu \mathrm{l}$ LightCycler 480 Genotyping Master Mixture (Taq DNA polymerase, reaction buffer, $15 \mathrm{mM} \mathrm{MgCl}_{2}$, and a dNTP mixture with UTP instead of dTTP) (Roche Applied Science; Mannheim, Germany).

The cycling program consisted of 10 minutes of initial denaturation at $95^{\circ} \mathrm{C}$, followed by 40 cycles of denaturation at $95^{\circ} \mathrm{C}$ for 5 seconds (ramp rate $4.4^{\circ} \mathrm{C} / \mathrm{s}$ ), annealing at $55^{\circ} \mathrm{C}$ for 10 seconds (ramp rate $2.2^{\circ} \mathrm{C} / \mathrm{s}$ ), and extension at $72^{\circ} \mathrm{C}$ for 10 seconds (ramp rate $4.4^{\circ} \mathrm{C} / \mathrm{s}$ ). After PCR melting curves were generated by holding the reaction mixture at $95^{\circ} \mathrm{C}$ for 1 minute, lowering the temperature to $55^{\circ} \mathrm{C}$ for 30 seconds, holding it for 30 seconds at $45^{\circ} \mathrm{C}$, followed by continuously heating to $80^{\circ} \mathrm{C}$. Melting curve analyses were conducted by means of the LightCycler 480 software according to the manufacturer's instructions (Roche Diagnostics Inc.; Mannheim, Germany).

\section{Statistical analysis}

Genotype distributions and allele frequencies of the EPHX2 K55R polymorphism in CHD patients and controls or the analysed subgroups were compared by chisquare test using a free program http://statpages.org/ ctab2x2.html. For all data, the association was considered to be significant for $\mathrm{p}<0.05$.

Genotypes were tested for Hardy-Weinberg equilibrium among MI cases and controls using a chi-square test with one degree of freedom.

\section{Results}

\section{Study population}

A comparison of the baseline clinical characteristics and the procedural parameters of CHD cases and controls is presented in Table 1.

The age of the CHD patients compared to the controls was approximately equal in both groups $(61 \pm 8.9$ versus $59 \pm$ 9.6). However, the proportion of male subjects was signif-

Table I: Baseline characteristics of the study population

\begin{tabular}{|c|c|c|}
\hline Characteristic & $\begin{array}{l}\text { CHD cases } \\
(n=435)\end{array}$ & $\begin{array}{l}\text { Controls } \\
(n=274)\end{array}$ \\
\hline Age at recruitment & $61 \pm 8.9$ & $59 \pm 9.6$ \\
\hline Men & $365(83.9)$ & $129(47.1)$ \\
\hline BMI -- kg/m² & $28 \pm 3.5$ & $27 \pm 5.3$ \\
\hline$\geq 30 \mathrm{~kg} / \mathrm{m}^{2}$ & $103(23.7)$ & 49 (I7.9) \\
\hline \multicolumn{3}{|l|}{ Medication } \\
\hline Verapamil & $220(50.6)$ & -- \\
\hline Placebo & $215(49.4)$ & -- \\
\hline \multicolumn{3}{|l|}{ Event } \\
\hline Intracoronary stent & $362(83.2)$ & -- \\
\hline Previous CABG & $17(3.9)$ & -- \\
\hline Previous PTCA & $43(9.9)$ & -- \\
\hline Previous MI & $156(35.9)$ & -- \\
\hline \multicolumn{3}{|l|}{ Cardiovascular risk factor } \\
\hline Diabetes mellitus & $54(12.4)$ & $22(8.0)$ \\
\hline Hypertension & $279(64.1)$ & $139(50.7)$ \\
\hline Hyperlipidaemia & $373(85.7)$ & $138(50.4)$ \\
\hline Current smoker & $103(23.7)$ & $40(14.6)$ \\
\hline Former smoker & $163(37.5)$ & 47 (I7.2) \\
\hline Family history of CHD & $166(38.2)$ & $\mathrm{n} / \mathrm{a}$ \\
\hline Restenosis & $128(29.4)$ & -- \\
\hline
\end{tabular}

Data presented are number (\%) of patients; plus-minus values are mean \pm standard deviation. $B M I$ body mass index, CABG coronary artery bypass grafting, PTCA percutaneous transluminal coronary angioplasty, MI myocardial infarction, CHD coronary heart disease, n/a not applicable. 
icantly higher in CHD patients than in the control group ( $83.9 \%$ versus $47.1 \%)$. As expected, patients suffering from coronary heart disease revealed a higher prevalence of hypertension, diabetes mellitus, hyperlipidaemia and smoking habit compared to the controls.

\section{EPHX2 K55R and restenosis}

CHD cases were subdivided into two groups according to the occurrence or lack of restenosis at the 6 month follow up. For the further analysis, no differentiation was made between patients with late lumen loss and angiographic restenosis.

Over this period, $29.4 \%$ of the investigated 435 patients developed a restenosis.

The EPHX2 K55R genotype distribution was determined and compared between both groups, whereby A/A represented the wild-type, $A / G$ the heterozygous and $G / G$ the homozygous mutant genotype.

The distribution was $82.0 \% \mathrm{~A} / \mathrm{A}$ and $18.0 \% \mathrm{~A} / \mathrm{G}+\mathrm{G} / \mathrm{G}$ in patients with restenosis compared to $82.1 \% \mathrm{~A} / \mathrm{A}$ and $17.9 \% \mathrm{~A} / \mathrm{G}+\mathrm{G} / \mathrm{G}$ in patients without $(\mathrm{p}=0.989)$ (Table $2)$. Hence, this analysis failed to show any significant influence of the EPHX2 K55R polymorphism on angiographic restenosis after PCI.

Additionally, an alignment of the genotype distribution was conducted in subgroups of CHD patients who received verum $(n=220)$ and placebo $(n=215)$ to ensure an approximately equal distribution in these groups. With this analysis, any effects on the development of restenosis by random interactions between medication and genotype were excluded (Data not shown).

\section{EPHX2 K55R and CHD}

In order to confirm the previously reported association of EPHX2 K55R with an increased risk of CHD the genotype and allele frequencies in 435 CHD patients and 271 con-

Table 2: EPHX2 K55R in restenosis and non-restenosis patients

\begin{tabular}{llll}
\hline & $\begin{array}{l}\text { CHD cases } \\
\text { Restenosis } \\
(\mathbf{n}=128)\end{array}$ & $\begin{array}{l}\text { CHD cases } \\
\text { No Restenosis } \\
(\mathbf{n}=\mathbf{3 0 7})\end{array}$ & P value \\
\hline $\begin{array}{l}\text { Genotype } \\
\text { A/A }\end{array}$ & $105(82.0)$ & $252(82.1)$ & \\
A/G + G/G & $23(18.0)$ & $55(17.9)$ & 0.989 \\
Allele frequencies & & & \\
A & 0.91 & 0.91 & \\
G & 0.09 & 0.09 &
\end{tabular}

Data presented as absolute (\%) genotype frequency and allele frequency. trols with no pathological findings shown by coronary angiography, were analysed. The genotype distribution did not significantly $(\mathrm{P}>0.1)$ deviate from the HardyWeinberg equilibrium (Table 3 ).

As demonstrated in table 3 the distribution of genotypes was $82.1 \% \mathrm{~A} / \mathrm{A}$ and $17.9 \% \mathrm{~A} / \mathrm{G}+\mathrm{G} / \mathrm{G}$ in $\mathrm{CHD}$ cases versus $80.8 \% \mathrm{~A} / \mathrm{A}$ and $19.2 \% \mathrm{~A} / \mathrm{G}+\mathrm{G} / \mathrm{G}$ in the control group $(p=0.675)$. Consequently, no statistically significant differences in the distribution of genotypes of CHD cases compared to controls could be observed. Thus, the association of the K55R allele variant with CHD could not be confirmed in the examined study population.

Additional analysis was performed to investigate the potential relevance of EPHX2 K55R to the early-onset of CHD. Therefore, male patients with early-onset CHD, defined as clinical CHD occurring at the age of $\leq 55$ years and matched controls were divided into groups and statistical analysis was performed. This analysis also showed no significant difference in the genotype distribution and allele frequencies of CHD cases and controls according to the age of the subjects (Table 3 ).

\section{EPHX2 K55R and risk of hypertension}

To investigate the correlation between increased risk of hypertension and the $K 55 R$ variant allele subgroup analysis was conducted. The EPHX2 K55R genotype distribution in patients with raised blood pressure was $83.5 \% \mathrm{~A} /$ $\mathrm{A}$ and $16.5 \% \mathrm{~A} / \mathrm{G}+\mathrm{G} / \mathrm{G}$ in $\mathrm{CHD}$ cases versus $83.2 \% \mathrm{~A} / \mathrm{A}$ and $16.8 \% \mathrm{~A} / \mathrm{G}+\mathrm{G} / \mathrm{G}$ in the control group (Table 4 ). Therefore, the $K 55 R$ variant allele was not significantly associated with an increased risk of hypertension ( $\mathrm{p}=$ $0.938)$.

None of the other cardiovascular risk factors was significantly associated with a higher frequency of the risk variants $\mathrm{A} / \mathrm{G}$ and $\mathrm{G} / \mathrm{G}$ of the EPHX2 polymorphism in CHD patients examined by means of subgroup analysis (Table 4).

\section{Discussion}

Several polymorphisms within the EPHX2 gene have been reported to influence the enzyme activity and stability of soluble epoxide hydrolase causing alterations in EET levels $[29,30,32]$. Therefore, genetic variations in EPHX2 may affect the beneficial properties of EETs on the vascular system and thus, could be linked to risks for cardiovascular events $[26,27]$.

Based on the previously reported association of the EPHX2 K55R polymorphism with incident CHD in an American study population of Caucasian origin [28], we investigated whether the $K 55 R$ variant allele was associated with restenosis in patients who had undergone pri- 
Table 3: EPHX2 K55R genotype distribution in incident CHD and early-onset CHD cases

\begin{tabular}{|c|c|c|c|c|c|c|c|}
\hline & $\begin{array}{l}\text { CHD } \\
(n=435)\end{array}$ & $\begin{array}{l}\text { Controls } \\
(n=27 I)\end{array}$ & $H W$ & $P$ value & $\begin{array}{l}C H D \\
55 \text { years } \\
(n=1 \mid 7)\end{array}$ & $\begin{array}{l}\text { Controls } \\
55 \text { years } \\
(n=91)\end{array}$ & $P$ value \\
\hline \multicolumn{8}{|l|}{ Genotype } \\
\hline $\mathrm{A} / \mathrm{A}$ & $357(82.1)$ & $219(80.8)$ & & & $92(78.6)$ & $75(82.4)$ & \\
\hline$A / G+G / G$ & $78(17.9)$ & $52(19.2)$ & 0.527 & 0.675 & $25(21.4)$ & $16(17.6)$ & 0.496 \\
\hline \multicolumn{8}{|c|}{ Allele frequencies } \\
\hline A & 0.91 & 0.90 & & & 0.89 & 0.91 & \\
\hline G & 0.09 & 0.10 & & & 0.11 & 0.09 & \\
\hline
\end{tabular}

Data presented as absolute (\%) genotype frequency and allele frequency. HW: P-value for Hardy-Weinberg equilibrium test.

mary successful PCI. Our results demonstrate no significant correlation between the EPHX2 variant and the occurrence of restenosis within 6 month after PCI investigated by means of subgroup analysis. None of the known risk factors for restenosis, such as diabetes mellitus or hypertension, could be identified as the cause for the occurrence of restenosis in $29.4 \%$ of our patient cohort. We assume that late lumen loss in the studied patient cohort is mainly caused by hyperplasia of the vascular endothelium $[33,34]$. The findings in the present study indicate that an involvement of the EPHX2 K55R variant on this mechanism can largely been excluded.

As no association between $K 55 R$ and restenosis could be observed, we assumed that the previously reported association of the EPHX2 K55R polymorphism with incident CHD could be validated in the present study. However,

Table 4: EPHX2 K55R genotype distribution in subgroups of cardiovascular risk factors

\begin{tabular}{llll}
\hline & CHD cases & Controls & P value \\
\hline Hypertension & $n=279$ & $n=137$ & \\
A/A & $233(83.5)$ & $114(83.2)$ & \\
A/G + G/G & $46(16.5)$ & $23(16.8)$ & 0.938 \\
Male & $n=365$ & $n=126$ & \\
A/A & $299(81.9)$ & $106(84.1)$ & \\
A/G + G/G & $66(18.1)$ & $20(15.9)$ & 0.574 \\
Diabetes mellitus & $n=54$ & $n=20$ & \\
A/A & $44(81.5)$ & $17(85.0)$ & \\
A/G + G/G & $10(18.5)$ & $3(15.0)$ & 0.724 \\
& & & \\
Hyperlipidaemia & $n=373$ & $n=133$ & \\
A/A & $304(81.5)$ & $106(79.7)$ & \\
A/G + G/G & $69(18.5)$ & $27(20.3)$ & 0.649 \\
& & & \\
Current Smoker & $n=103$ & $n=39$ & \\
A/A & $87(84.5)$ & $31(79.5)$ & \\
A/G + G/G & $16(15.5)$ & $8(20.5)$ & 0.480
\end{tabular}

Data presented as absolute (\%) genotype frequency and allele frequency in subgroups for cardiovascular risk factor. we could not observe this association with the incidence of CHD in the present study.

It was shown that the association of polymorphisms within the EPHX2 gene with cardiovascular risks strongly depends on the ethnical background of the analysed populations [26,35]. Indeed, the reported association could only be observed in Caucasian CHD cases and not in African-Americans. The CHD cases in our study were of Caucasian origin, hence this could not explain the contrary findings of the both studies. However, due to the inclusion of patients who were exclusively from Central Europe and the resulting well defined demography it is assumed that the ethnical background of our study cohort is more homogenous than in the previously reported study.

Furthermore, in the reported study the mean age of the population was significantly younger (CHD cases: $55.8 \pm$ 0.17 years, controls: $53.8 \pm 0.10$ years) than in the present study. This indicates that association of EPHX2 K55R may be only detectable in early-onset CHD. To review this hypothesis, the genotype distribution in CHD cases as well as in the control group was analysed with respect to the age of the patients. Our findings revealed no significant difference in the genotype distribution when only patients aged $\leq 55$ years were analysed. This fact eliminates the possibility of an exclusive effect on early-onset CHD.

The fundamental difference of our study population compared to the previous study was the diagnostic inclusion criteria of the patients. In the present study all CHD patients had undergone a PCI with exclusion of cases suffering from acute coronary syndrome, whereas in the previously cited study more than half of all the patients suffered from acute myocardial infarction. The difference in patient characteristics may be the cause for the contrary findings.

Since several studies revealed an influence of EPHX2 gene expression on blood pressure by alterations in EET levels, 
the association of the $K 55 R$ variant with increased risk of hypertension was investigated. Our findings showed no correlation between the EPHX2 K55R variant and decreased blood pressure in the studied population. Previous studies revealed that changes in blood pressure are accompanied with alterations in the epoxide enzyme activity. For instance, higher soluble epoxide hydrolase activity in carriers of at least one $K 55 R$ variant allele was described in CHD patients of Caucasian origin [28]. In our study the enzyme activity of the soluble epoxide hydrolase and EET levels were not quantified because they where not defined as target parameters of this genetic study.

To our knowledge, the present study is the first to investigate the effect of the EPHX2 K55R polymorphism on the occurrence of restenosis after primary successful PCI. However, not even an association with incident CHD could be confirmed.

Certainly, the value of our results is limited due to the relatively low number of analysed individuals. Assuming a case-control design and type I error $\alpha=0.05$, we had a power of 0.47 to detect proportions of the K55R variant allele of $20.8 \%$ in CHD cases and $15.3 \%$ in the controls derived from the previous report [28]. It has to be noted that, in genome wide scans of large patient cohorts, no association was found between CHD and the locus of EPHX2 on chromosome 8p21-p12 [36]. This fact supports the findings of the present study.

\section{Conclusion}

The results of the present study show no significant association of the EPHX2 K55R allele variant with the development of restenosis in patients over a period of six month after PCI. Furthermore, the association of this genetic variant with incident CHD could not even confirmed.

In conclusion, the present results suggest that the EPHX2 K55R polymorphism can be excluded as independent predictor for coronary heart disease or for the occurrence of restenosis in patients who had undergone primary successful PCI.

\section{Competing interests}

The authors declare that they have no competing interests.

\section{Authors' contributions}

SK established and performed the genotyping, analyzed the data and drafted the manuscript. PB administrated the blood samples and the clinical data. KR performed the DNA preparation and sample management. AH critically evaluated the statistics. GH, ML and RF revised the phenotype data and the manuscript. HPB designed and coordinated the clinical study and performed the enrolling and phenotyping of the patients. EvH provided the blood samples and the patients baseline characteristics of the controls. TS designed the genetic studies, made adjuvant contributions to the interpretation of the results and critically revised the manuscript. All authors have read and approved the final manuscript.

\section{Acknowledgements}

We would like to thank J. Davies for linguistic corrections.

\section{References}

I. McBride W, Lange RA, Hillis LD: Restenosis after successful coronary angioplasty. Pathophysiology and prevention. $N$ Engl J Med 1988, 3 18(26): 1734- 1737.

2. Cohen DJ, Doucet M, Cutlip DE, Ho KK, Popma JJ, Kuntz RE: Impact of smoking on clinical and angiographic restenosis after percutaneous coronary intervention: another smoker's paradox? Circulation 200I, 104(7):773-778.

3. Loutfi M, Mulvihill NT, Boccalatte M, Farah B, Fajadet J, Marco J: Impact of restenosis and disease progression on clinical outcome after multivessel stenting in diabetic patients. Catheter Cardiovasc Interv 2003, 58(4):45I-454.

4. Fattori R, Piva T: Drug-eluting stents in vascular intervention. Lancet 2003, 36 I (9353):247-249.

5. Rosanio S, Tocchi M, Patterson C, Runge MS: Prevention of restenosis after percutaneous coronary interventions: the medical approach. Thromb Haemost 1999, 82(Suppl I): 164-170.

6. Gruberg L, Waksman R, Satler LF, Pichard AD, Kent KM: Novel approaches for the prevention of restenosis. Expert Opin Investig Drugs 2000, 9(I I):2555-2578.

7. Petrovic $D$, Peterlin $B$ : Genetic markers of restenosis after coronary angioplasty and after stent implantation. Med Sci Monit 2005, I I (4):RAI27-I35.

8. Monraats PS, W RPA, Jukema JW: Genetic predictive factors in restenosis. Pathol Biol (Paris) 2004, 52(4): 186-195.

9. Roman RJ, Maier KG, Sun CW, Harder DR, Alonso-Galicia M: Renal and cardiovascular actions of 20-hydroxyeicosatetraenoic acid and epoxyeicosatrienoic acids. Clin Exp Pharmacol Physiol 2000, 27( I I):855-865.

10. Sarkis A, Lopez B, Roman RJ: Role of 20-hydroxyeicosatetraenoic acid and epoxyeicosatrienoic acids in hypertension. Curr Opin Nephrol Hypertens 2004, 13(2):205-2I4.

II. Campbell WB, Gebremedhin D, Pratt PF, Harder DR: Identification of epoxyeicosatrienoic acids as endothelium-derived hyperpolarizing factors. Circ Res 1996, 78(3):4I5-423.

12. Imig JD, Navar LG, Roman RJ, Reddy KK, Falck JR: Actions of epoxygenase metabolites on the preglomerular vasculature. J Am Soc Nephrol 1996, 7(II):2364-2370.

13. Imig JD, Zhao X, Capdevila JH, Morisseau C, Hammock BD: Soluble epoxide hydrolase inhibition lowers arterial blood pressure in angiotensin II hypertension. Hypertension 2002, 39(2 Pt 2):690-694.

14. Node K, Huo Y, Ruan X, Yang B, Spiecker M, Ley K, Zeldin DC, Liao JK: Anti-inflammatory properties of cytochrome $\mathbf{P 4 5 0}$ epoxygenase-derived eicosanoids. Science 1999, 285(543I): $1276-1279$

15. Campbell WB: New role for epoxyeicosatrienoic acids as antiinflammatory mediators. Trends Pharmacol Sci 2000, 21(4): I25-127.

16. Krotz F, Riexinger T, Buerkle MA, Nithipatikom K, Gloe T, Sohn HY, Campbell WB, Pohl U: Membrane-potential-dependent inhibition of platelet adhesion to endothelial cells by epoxyeicosatrienoic acids. Arterioscler Thromb Vasc Biol 2004, 24(3):595-600.

17. Larsen BT, Gutterman DD, Hatoum OA: Emerging role of epoxyeicosatrienoic acids in coronary vascular function. Eur J Clin Invest 2006, 36(5):293-300.

18. Spiecker M, Liao JK: Vascular protective effects of cytochrome p450 epoxygenase-derived eicosanoids. Arch Biochem Biophys 2005, 433(2):413-420.

19. Spector AA, Fang X, Snyder GD, Weintraub NL: Epoxyeicosatrienoic acids (EETs): metabolism and biochemical function. Prog Lipid Res 2004, 43(I):55-90. 
20. Yu Z, Xu F, Huse LM, Morisseau C, Draper AJ, Newman JW, Parker C, Graham L, Engler MM, Hammock BD, et al:: Soluble epoxide hydrolase regulates hydrolysis of vasoactive epoxyeicosatrienoic acids. Circ Res 2000, 87( I I):992-998.

21. Corenblum MJ, Wise VE, Georgi K, Hammock BD, Doris PA, Fornage $M$ : Altered soluble epoxide hydrolase gene expression and function and vascular disease risk in the stroke-prone spontaneously hypertensive rat. Hypertension 2008, 5 I (2):567-573.

22. Fornage M, Hinojos CA, Nurowska BW, Boerwinkle E, Hammock $\mathrm{BD}$, Morisseau $\mathrm{CH}$, Doris PA: Polymorphism in soluble epoxide hydrolase and blood pressure in spontaneously hypertensive rats. Hypertension 2002, 40(4):485-490.

23. Sinal CJ, Miyata M, Tohkin M, Nagata K, Bend JR, Gonzalez FJ: Targeted disruption of soluble epoxide hydrolase reveals a role in blood pressure regulation. I Biol Chem 2000, 275(5 I):40504-405I0.

24. Luria $A$, Weldon $S M$, Kabcenell $A K$, Ingraham $R H$, Matera $D$, Jiang $H$, Gill R, Morisseau C, Newman JW, Hammock BD: Compensatory mechanism for homeostatic blood pressure regulation in Ephx2 gene-disrupted mice. J Biol Chem 2007 282(5):289|-2898.

25. Fang X, Weintraub NL, McCaw RB, Hu S, Harmon SD, Rice JB, Hammock BD, Spector AA: Effect of soluble epoxide hydrolase inhibition on epoxyeicosatrienoic acid metabolism in human blood vessels. Am J Physiol Heart Circ Physiol 2004, 287(6): $\mathrm{H} 24 \mid 2-2420$.

26. Wei Q, Doris PA, Pollizotto MV, Boerwinkle E, Jacobs DR Jr, Siscovick DS, Fornage M: Sequence variation in the soluble epoxide hydrolase gene and subclinical coronary atherosclerosis: interaction with cigarette smoking. Atherosclerosis 2007, 190(I):26-34.

27. Burdon KP, Lehtinen $A B$, Langefeld $C D$, Carr JJ, Rich SS, Freedman $B I$, Herrington D, Bowden DW: Genetic analysis of the soluble epoxide hydrolase gene, EPHX2, in subclinical cardiovascular disease in the Diabetes Heart Study. Diab Vasc Dis Res 2008, 5(2): $128-134$.

28. Lee CR, North KE, Bray MS, Fornage M, Seubert JM, Newman JW, Hammock BD, Couper DJ, Heiss G, Zeldin DC: Genetic variation in soluble epoxide hydrolase (EPHX2) and risk of coronary heart disease: The Atherosclerosis Risk in Communities (ARIC) study. Hum Mol Genet 2006, I 5(10):1640-1649.

29. Sandberg M, Hassett C, Adman ET, Meijer J, Omiecinski Cl: Identification and functional characterization of human soluble epoxide hydrolase genetic polymorphisms. J Biol Chem 2000, 275(37):28873-2888I.

30. Przybyla-Zawislak BD, Srivastava PK, Vazquez-Matias J, Mohrenweiser HW, Maxwell JE, Hammock BD, Bradbury JA, Enayetallah AE, Zeldin DC, Grant DF: Polymorphisms in human soluble epoxide hydrolase. Mol Pharmacol 2003, 64(2):482-490.

31. Bestehorn HP, Neumann FJ, Buttner HJ, Betz P, Sturzenhofecker $P$, von Hodenberg E, Verdun A, Levai L, Monassier JP, Roskamm H: Evaluation of the effect of oral verapamil on clinical outcome and angiographic restenosis after percutaneous coronary intervention: the randomized, double-blind, placebo-controlled, multicenter Verapamil Slow-Release for Prevention of Cardiovascular Events After Angioplasty (VESPA) Trial. Am Coll Cardiol 2004, 43( I 2):2160-2 I65.

32. Srivastava PK, Sharma VK, Kalonia DS, Grant DF: Polymorphisms in human soluble epoxide hydrolase: effects on enzyme activity, enzyme stability, and quaternary structure. Arch Biochem Biophys 2004, 427(2): 164-169.

33. Nakatani M, Takeyama Y, Shibata M, Yorozuya M, Suzuki H, Koba S, Katagiri T: Mechanisms of restenosis after coronary intervention: difference between plain old balloon angioplasty and stenting. Cardiovasc Pathol 2003, I 2(I):40-48.

34. Schwartz RS, Henry TD: Pathophysiology of coronary artery restenosis. Rev Cardiovasc Med 2002, 3(Suppl 5):S4-9.

35. Fornage M, Lee CR, Doris PA, Bray MS, Heiss G, Zeldin DC, Boerwinkle $E$ : The soluble epoxide hydrolase gene harbors sequence variation associated with susceptibility to and protection from incident ischemic stroke. Hum Mol Genet 2005, I 4(19):2829-2837.

36. Kathiresan S, Voight BF, Purcell S, Musunuru K, Ardissino D, Mannucci PM, Anand S, Engert JC, Samani NJ, Schunkert H, et al.: Genome-wide association of early-onset myocardial infarc- tion with single nucleotide polymorphisms and copy number variants. Nat Genet 2009, 4 I (3):334-4I.

\section{Pre-publication history}

The pre-publication history for this paper can be accessed here:

http://www.biomedcentral.com/1471-2261/9/48/prepub
Publish with Biomed Central and every scientist can read your work free of charge

"BioMed Central will be the most significant development for disseminating the results of biomedical research in our lifetime. "

Sir Paul Nurse, Cancer Research UK

Your research papers will be:

- available free of charge to the entire biomedical community

- peer reviewed and published immediately upon acceptance

- cited in PubMed and archived on PubMed Central

- yours - you keep the copyright 